\title{
Regulations on the Corporate Social Irresponsibility in the Supply Chain under the Multiparty Game: Taking China's Organic Food Supply Chain as an example
}

\author{
Zhiqiang Ma ${ }^{\mathrm{a}}$, Jiajia Chen ${ }^{\mathrm{a}}$, Gang Tian ${ }^{\mathrm{a}}$, Yu Gong ${ }^{\mathrm{b}}$, Benhai Guo ${ }^{\mathrm{c}}$, Faxin Cheng ${ }^{\mathrm{a}}$ \\ a School of Management, Jiangsu University, Zhenjiang, 212013, China \\ b Southampton Business School, University of Southampton, Southampton, SO17 1BJ, UK \\ c College of Economics and Management, China Jiliang University, Hangzhou, 310018, \\ China
}

\begin{abstract}
This paper considers the lack of corporate social responsibility in the organic food supply chain in a new context, that is, the fraudulent subsidies claiming behavior of the manufacturers and the lack of organic food supervision of the fast-growing e-commerce retailers in China. We construct a three-party evolutionary game model among government regulatory departments, manufacturers and e-commerce retailers to analyze the evolution process of the behaviors of manufacturers and ecommerce retailers under government's changing regulation. The results show that: (1) The government can promote the production of organic food by the moderate supervision of manufacturers; Low intensity supervision cannot restrain fraudulent subsidies claiming behavior, while high intensity supervision will restrain the orderly development of organic food industry. (2) The greater the government subsidies on technology and R \& D of manufacturers, the more conducive the manufacturerss will be to overcome technical problems and realize the scale of the organic food industry, so that it will eventually evolve towards the direction of active production of organic food. (3) The government's low-intensity fine on e-commerce retailers when they fail to fulfill their responsibilities is not enough to prompt them to choose the strategy of responsibility fulfillment, and the greater the fine is, the more conducive it is for them to evolve towards fulfilling their social responsibilities. (4) Appropriate government funding for e-commerce retailers will encourage them to fulfill their responsibility, but excessive funding will make e-commerce retailers over rely on government funding. Our research provides a better understanding of the irresponsible behavior of organic food supply chain enterprises, our management insights can help improve the government's regulation performance of such behavior, and can also provide a reference for other countries facing similar challenges.
\end{abstract}

Keywords: Organic food; Corporate social irresponsibility; Government regulation; Evolutionary game 



\section{Introduction}

Food safety has always been a worldwide problem, and even developed countries are plagued by food safety issues. According to statistics, in the United States about 48 million people suffered from foodborne illness, about 3,000 of them died each year; there are 350 food safety incidents a year on average in the United Stated, and the economic loss caused by food pollution is as much as US\$152 billion (Dewey-Mattia, 2018). The famous Japanese pastry company, Fujiya was exposed for using expired milk and eggs to make cream puff (Louis et al., 2018). The Irish Food Safety Officer found hamburgers contaminated with horse meat, which was substituted for beef in the ready-to-eat food. In this incident, Tesco, Lidl, Aldi, Iceland and other large retailers had to remove about 10 million hamburgers from shelves (Food Safety Authority of Ireland, 2013).

As a major producer and consumer of food, China has been plagued by food corporate social irresponsibility problems for many years. Since the Reform and Opening up of the country, the rapid development of China's food supply chain has produced huge economic benefits. However, for many years, a series of food corporate social irresponsibility incidents, such as "problem milk powder", "cadmium rice", "toxic cowpea" and "lean meat powder", have occurred frequently throughout China (Liu et al., 2015; Wu et al., 2018). In addition, excessive use of chemical fertilizers and pesticides has caused serious environmental pollution (Paul et al., 2016; Patel et al., 2017). The emergence of these events is of great concern to the community, and has also raised the concern of social responsibility and sustainable development of food supply chain.

At present, the Chinese government has realized that the development of the food supply chain should not simply consider economic benefits; it must also pay attention to social and environmental responsibilities. To this end, local governments in China have begun to vigorously push the development of safe and pollution-free "organic food" (You et al., 2016; Zheng et al., 2017), hoping to improve the social responsibility awareness and level of food supply chain enterprises, and promote the transformation and upgrading of the food industry for long-term sustainable development.

China's organic food distribution channels mainly rely on traditional offline channels. However, offline channels have many problems, such as excessive circulation nodes, low degree of information and imperfect quality tracing system. These not only lead to high costs, but also greatly restrict the fulfilment of supply chain social responsibility. As the Internet's application range continues to expand, e-commerce-based online channels have also been introduced into the food supply chain. The e-commerce retailer reduces intermediate links in the supply chain and improves the efficiency of the supply chain. More importantly, the operation of the organic food supply chain in the e-commerce environment is more transparent and easier to trace than the traditional supply chain, which makes it possible to solve the social irresponsibility problem of the organic food supply chain.

However, the lack of corporate social responsibility in China's organic food supply chain is also common. In fact, it is the social responsibility of organic food manufacturers to produce organic products in compliance and obtain certifications. On the other hand, it is also the social responsibility of e-commerce retailers to inspect the organic food sold to ensure that consumers are provided with qualified organic food. Enterprises need to pay a large cost to fulfill their social responsibility. In practice, instead of increasing technical input into the production of organic products, some 
manufacturers ignore their social responsibilities and cheat government subsidies by imitating and counterfeiting organic food certification marks. At the same time, some e-commerce retailers avoid fulfilling their social responsibilities and lack effective inspection of the organic food they sell, which provides manufacturers with the opportunity to seek profits by counterfeiting. In recent years, many social ilresponsible incidents of organic food manufacturers and e-commerce retailers have occurred from time to time. According to the data of China Organic Food Development Center, in 2018, a total of 32 products in China had their labels cancelled due to unqualified inspection. In the same year, 124 non-standard products and 13 fake products were also processed, accounting for $8.01 \%$ and $0.85 \%$ respectively (Mao, 2019). Chinese media have exposed "unspoken rules" in food sold by e-commerce enterprises. At present, on the online platforms of e-commerce retailers, there are still many manufacturers selling products without national organic certification in the name of "organic and healthy" and "organic and organic without pesticide and chemical fertilizer", while ecommerce retailers often acquiesce in this behavior (Xinhuanet, 2017).

On the one hand, the profit of irresponsible manufacturers will cause other manufacturers in the same industry to follow suit, which will have an impact on the enterprises that really provide organic food, resulting in the phenomenon of "bad money driving out good money". On the other hand, the chaotic market order and fraud caused by the irresponsible e-commerce retailers also hit consumers' confidence in organic food. Such factors seriously affect the fulfillment of social responsibility and sustainable development of the organic food supply chain. According to the information disclosed by the Chinese government and media in recent years, China's organic food industry is still developing slowly. The phenomenon of "bad money expels good money" makes other enterprises unwilling to enter the organic food industry. In addition, there is a deviation between consumers' satisfaction with organic food and the government's expectation, resulting in a large gap between the actual promotion amount and the planned promotion amount.

Government is an important external counterbalance force of organic food supply chain, how to effectively regulate organic products and urge manufacturers and e-commerce retailers to actively fulfill their social responsibilities is of great significance to promote the development of organic food market, the transformation and upgrading of China's agricultural products processing industry and the solution of food safety problems.

Existing literature focuses on the regulation of the government on the food supply chain from a certain aspect of regulation or subsidies. Few scholars combine regulation and subsidies to study how the government promotes the sustainable development of the organic food supply chain, and scholars generally ignore the lack of social responsibility of organic food enterprises(Rozman et al., 2013;Papadopoulos et al.,2018; Nie et al., 2020). In addition, many studies have shown that online retailers have great potential in promoting the fulfillment of corporate social responsibility in supply chain by taking advantage of their market position and influence on suppliers (Styles et al., 2012). However, the current literature on corporate social responsibility (CSR) is mainly limited to the manufacturing industry, with a lack of attention to the retail industry (Tang et al., 2016). In particular, the existing studies seldom pay attention to the regulatory misconduct of China's rapidly developing e-commerce retailers in the organic food supply chain. These deficiencies make it difficult for the existing research to provide valuable strategic reference for the government to effectively regulate the malfeasance behavior of organic food supply chain enterprises.

Based on this consideration, this paper combines government subsidies and punishment 
regulation strategies, and builds a three-party evolutionary game model between government regulatory agencies, organic food manufacturers and e-commerce retailers to analyze the evolution of the behavior of manufacturers and e-commerce retailers under government regulations, and try to answer the following questions:

(1) How to promote manufacturers to increase technology investment through government regulations and actively produce organic food?

(2) How to effectively eliminate fraudulent subsidies claiming behavior of food manufacturers?

(3) How to promote e-commerce retailers to actively fulfill their social responsibilities?

This research makes several original contributions. First, it contributes to the literature by advancing the understanding of food supply chains - integrating both subsidy and punishment strategies beyond traditional which focus either on subsidies or punishment. Second, this study develops an analysis framework based on evolutionary game to identify behavior strategies in the interaction of game players. Third, to the best of our knowledge, this is the first attempt to research regulation on the social irresponsibility such as fraudulent subsidies claiming behavior of Chinese organic food manufacturers. Fourth, the research offers an analysis of the impact of multiple stakeholders on the operation of the organic food supply chain, going beyond the dominant government-manufacturer viewpoint to the government-manufacturer-platform perspective which includes downstream supply chain members, such as e-commerce retailers, who are ignored by previous research. Finally, this research provides practical insights into regulating social irresponsibility of organic food supply chain enterprises in China, which may also apply to other countries and industries which face similar challenges.

The rest of this paper is arranged as follows: next section presents the literature review, the third part describes the model construction and research hypothesis, the fourth part carries out the evolutionary game equilibrium analysis, the fifth part provides the simulation analysis and results, and the last part concludes and provides policy recommendations.

\section{Literature Review}

The literature related to this paper mainly includes: government regulation of food market, production and consumption of organic food, supervision of food safety along the supply chain.

As a big country of food production and consumption, the operation of food supply chain in China has always been a research hotspot. Especially in recent years, a series of food safety accidents occur frequently. Therefore, many studies discuss the solution of food safety problems from the perspective of government regulations. Part of the research is from the perspective of government punishment. Song et al. (2018) studied the quality of food safety information disclosure in the traceability system, and proposed that government punishment should be increased, government supervision cost should be reduced, and social supervision should be improved, so as to clean up the false information in the food safety market. Pouliot and Wang (2018) examined the role of government in food safety, and pointed out that it is of great significance for food enterprises to provide safer food through direct intervention or indirect intervention measures such as increasing food testing. Nie et al. (2020) designed a punitive supervision mode with high punishment and low implementation cost to solve the problem of ineffective supervision measures on manufacturers' violations, and proposed that the supervision department should set up a more severe punishment system to restrain manufacturers' and retailers' violations. Song and Zhuang (2016) established a 
government manufacturer game model to solve the problem of food manufacturers adding chemicals, and analyzed the manufacturer's optimal response and the government's optimal punishment strategy. Wang et al. (2019) constructed an evolutionary game model for food adulteration behavior, and pointed out that the strictest supervision, the strictest punishment and the most serious accountability can effectively minimize the adulteration willingness of food enterprises, so as to achieve long-term stability of food safety. Fan and Li (2011) built an evolutionary game model for the violations of dairy manufacturers. The analysis results show that only the government departments increase the supervision and punishment of inferior dairy products, can the quality of dairy products be improved and the healthy development of dairy industry be promoted.

Some scholars have also analyzed the role of government subsidies. Chen et al. (2017) discussed the impact of agricultural subsidies on enterprise decision-making, compared quantitative subsidies and innovation subsidies, and put forward relevant suggestions for China's agricultural development. Zhao et al. (2017) discussed the impact of market incentive and government regulation on pesticide application behavior of vegetable farmers in China, and pointed out that farmers' income incentive has an important impact on their pesticide application behavior, and government regulation can provide a good environment for market incentive. Most of the existing government regulations on the food market focus on the traditional food market, and lack of attention on organic food. Moreover, most of these studies focus on one aspect of government punishment or subsidy, and lack of research on the combination of punishment and subsidy. The difference between this paper and them is that this paper focuses on the organic food market and combines government punishment with subsidies.

With the traditional agricultural pollution becoming more and more serious, in order to effectively improve the quality of food safety and reduce environmental pollution, countries began to develop organic food. As an emerging industry, the development of organic food has been paid more and more attention by many scholars. At present, the research on organic food mainly focuses on organic production and consumption. On the production and supply of organic food, Ni (2012) believes that the obstacle to the development of China's organic agricultural products industry is the insufficient supply of pollution-free agricultural products and non-staple foods, which do not meet consumers' demands for organic consumption of fruits, vegetables and meat. Varinder (2014) used fuzzy TOPSIS decision-making model to analyze the obstacles of government and industry in organic production from the environmental, social and economic aspects, and found that technical risk, lack of awareness and weak legislation are the three most important influencing factors of organic production. Zhang (2008) and Yin et al. (2010) believed that the government is the main promoter of organic agriculture, which has a positive impact on consumer trust. However, the government's work is imperfect in organic production technology diffusion, organic subsidies and supervision, which also hinders the development of the organic food market to some extent. Papadopoulos et al. (2018) analyzed the production motivation of organic agriculture. The results show that whether farmers implement organic agriculture is mainly determined by their attitude towards organic agriculture and government subsidies. However, there are also a series of problems in the development of organic food market. In the past decade, the number of certified organic food in China has increased dramatically, but the authenticity of organic food has become a huge hidden danger. Some so-called "organic vegetables" confuse the real with the fake, causing great damage to consumers' rights, trust, and purchasing confidence. In view of the problems in the development of organic food, there are also a few studies on the regulation of organic food market. Rozman et al. 
(2013) constructed a system dynamics model of organic agriculture development to support government decision-making, and its research pointed out that subsidies are the main motivation for the transformation from traditional agriculture to organic agriculture. In this article, we also pay attention to the fraudulent subsidies claiming behavior of manufacturers, which is lack of attention in the existing literature.

In recent years, with the development of online shopping, food has become a new growth point. However, due to the virtual nature of online food transaction, online food brings convenience to consumers, but also brings some hidden dangers, and brings difficulties to the sales supervision of online food. Some scholars pointed out that retailers such as third-party platforms can play a key role in establishing a sustainable food chain (Zhang et al., 2019; Naik et al., 2018). In the online food market, the behavior of enterprises is directly supervised by the platform department. These platforms are responsible for qualification examination, information registration and supervision in the sales process (Yan, and Yu, 2018). In this regard, Zhang (2018) studied the game relationship among regulatory authorities, the third-party network platform and online stores from the perspective of evolutionary game strategy. The results showed that the third-party network platform should give full play to its role in the process of online food safety supervision, and coordinate the food safety supervision between the third-party network platform and regulatory agencies. The existing research focuses on consumers' purchasing behavior and influencing factors, and lacks the attention of e-commerce retailers which have developed rapidly in recent years to the supervision of organic food they sell. Although a few scholars have noticed that e-commerce retailers can play a positive role, these studies do not consider the problem of e-commerce retailers' default which this research considered it.

Through the review of the existing literature, it can be found that there are a lot of studies on the production and consumption behavior of organic food, but few studies on the government regulation of organic food supply chain via both punishment and subsidies. In particular, there is a lack of research on the regulation of fraudulent subsidies claiming behavior of organic food manufacturers. And in the organic food supply chain under the background of e-commerce, there is also a lack of research on how to regulate e-commerce retailers' default behavior. The most relevant literatures of this study are Cui (2018), Chen (2017), Shen (2019) and Zhang (2018). Table 1 highlights the differences between the existing studies and this research.

Table 1 The differences between the existing literatures and our study

\begin{tabular}{|c|c|c|c|c|c|}
\hline & $\begin{array}{l}\text { Herui Cui } \\
\text { (2018) }\end{array}$ & $\begin{array}{c}\text { You-hua } \\
\text { Chen } \\
\text { (2017) }\end{array}$ & $\begin{array}{l}\text { Cong Shen } \\
\text { (2019) }\end{array}$ & $\begin{array}{l}\text { Hao Zhang } \\
\text { (2018) }\end{array}$ & $\begin{array}{l}\text { This } \\
\text { study }\end{array}$ \\
\hline $\begin{array}{l}\text { Whether to consider government } \\
\text { punishment }\end{array}$ & $\sqrt{ }$ & $x$ & $\sqrt{ }$ & $x$ & $\sqrt{ }$ \\
\hline $\begin{array}{l}\text { Whether to consider government } \\
\text { subsidies }\end{array}$ & $\sqrt{ }$ & $\sqrt{ }$ & $x$ & $\times$ & $\sqrt{ }$ \\
\hline $\begin{array}{l}\text { Whether to consider fraudulent } \\
\text { subsidies claiming by } \\
\text { manufactures }\end{array}$ & $x$ & $\times$ & $\times$ & $\times$ & $\sqrt{ }$ \\
\hline $\begin{array}{l}\text { Whether to consider e-commerce } \\
\text { retailers' supervision }\end{array}$ & $x$ & $x$ & $x$ & $\sqrt{ }$ & $\sqrt{ }$ \\
\hline
\end{tabular}




\begin{tabular}{l}
$\begin{array}{l}\text { Whether to consider e-commerce } \\
\text { retailers' social irresponsibility }\end{array}$ \\
\hline
\end{tabular}

\section{Construction of the three-party evolutionary game}

In real economic activities, it is difficult for both enterprises and governments to be completely rational. Their decisions often influence and restrict each other, and they are constantly adjusted according to the decisions of other subjects to maximize their own interests. Evolutionary game theory, as a method to deal with the bounded rationality of decision makers, has been widely used in supply chain management research (Zhang, L. et al.,2020; Sun, H. et al.,2019; Cui, H. et al.,2020). It combines the game theory with dynamic evolution process, emphasizes the game balanced decision-making should be the outcome of dynamic learning, the adjustment and trial and error. It overcomes the traditional theory of ignoring the bounded rationality and game dynamic process, is able to reveal the organic food market main body in the interactive behaviors, helps to understand the decision problem of organic food regulation in the relevant subject.

\subsection{Model assumptions}

\section{(1) Behavior strategies of game players}

The participants in the game process are the government, organic food manufacturers and ecommerce retailers, and all of them are bounded rational. Each party of the game has two strategies. The government can choose to apply two kinds of behavior strategy: "positive regulation" and "negative regulation". When the government chooses negative regulation, it only grants certain subsidies to organic food manufacturers, but does not supervise and control the quality of organic food and other problems. When it chooses positive regulation, the government will give financial subsidies to organic food manufacturers, and at the same time regulate the behavior of these manufacturers. This is because, some food manufacturers, due to the inferior technology and poor production management, put products produced that do not meet the requirements of organic food into the market, and engage in fraudulent behavior to secure financial support from government. At the same time, the environmental pollution caused by non-organic production is punished to encourage manufacturers to produce organic food. On the other hand, financial subsidies will be given to e-commerce retailers that fulfill their social responsibilities, and penalties will be given to e-commerce retailers that fail to fulfill their responsibilities. Manufacturers can choose to "to produce" or "not to produce" organic food; e-commerce retailers can choose to "fulfill their responsibilities" or "fail to fulfill their responsibilities". In other words, they can check and control the quality of organic food sold on their platforms, or they can neglect their responsibilities by not inspecting and controlling the products sold on their platforms.

\section{(2) Model assumptions and the setting of relevant parameters}

Assumption 1: The three parties choose their own behavior with a certain probability. Assuming that, in the initial state, the probability of the e-commerce retailers choosing to fulfill its responsibilities is $x$, and the probability of choosing not to fulfill its responsibilities is $1-x$. The probability that the manufacturer chooses to produce organic food is $y$, and the probability that it chooses not to produce organic food is $1-y$. The probability that the government chooses active regulation is $z$, and the probability that it chooses negative regulation is $1-z$.

Assumption 2: In the evolutionary game model, when the government chooses negative regulation, it will give financial subsidy $I_{2}$ to the organic food manufacturer, and the subsidy 
intensity is $\xi$. If the government chooses active regulation, it will give the manufacturer financial subsidies. The former will supervise the behaviors of the latter and the punishment of fraudulent subsidies claiming behavior is $N$ and regulatory intensity is $\gamma$, so the loss of the manufacturer is $\gamma N$. Meanwhile the government will impose the manufacturer with penalty $Q$ that do not produce organic products by polluting the environment, and the penalty intensity is $\omega$. On the other hand, the government will provide financial funding $I_{1}$ to the e-commerce retailers that fulfill its social responsibilities, where the funding intensity is $\eta$, and the government will punish the e-commerce retailers with fine $P$ that fail to fulfill its responsibilities, where the fine intensity is $\lambda$.

Assumption 3: If the manufacture chooses not to produce organic food and the e-commerce retailers chooses not to fulfill its responsibility, the income of the two is, $\pi_{1}$ and $\pi_{2}$ respectively.

Assumption 4: The e-commerce retailers needs to pay inspection costs $C_{1}$ if it chooses to fulfill its responsibilities, but at the same time, with the improvement of product quality and safety degree, the proportion that can bring revenue increases is $\alpha(\alpha>0)$. For the manufacturer, the cost of producing organic food will increase by $C_{2}$, and the proportion of revenue increase is $\beta(\beta>0)$.

Assumption 5: When the e-commerce retailers chooses to fulfill its responsibilities and the manufacturer chooses not to produce, the e-commerce retailers improves its reputation and increase the demand for products by performing its responsibilities, so the manufacturer will gain additional benefits $T_{2}$ due to "free riding". When the manufacturer chooses to produce organic food and the e-commerce retailers chooses the strategy of not to fulfill its responsibilities, to some extent the input production cost of the manufacturer improves the quality and safety of food, and the e-commerce retailers will gain more reputation and increase economic income $T_{1}$ due to "free riding".

Based on the above basic assumptions and the setting of profit and loss variables, in order to better describe the game process among the government, food manufacturers and e-commerce retailers, the game tree is constructed as shown in Figure 1.

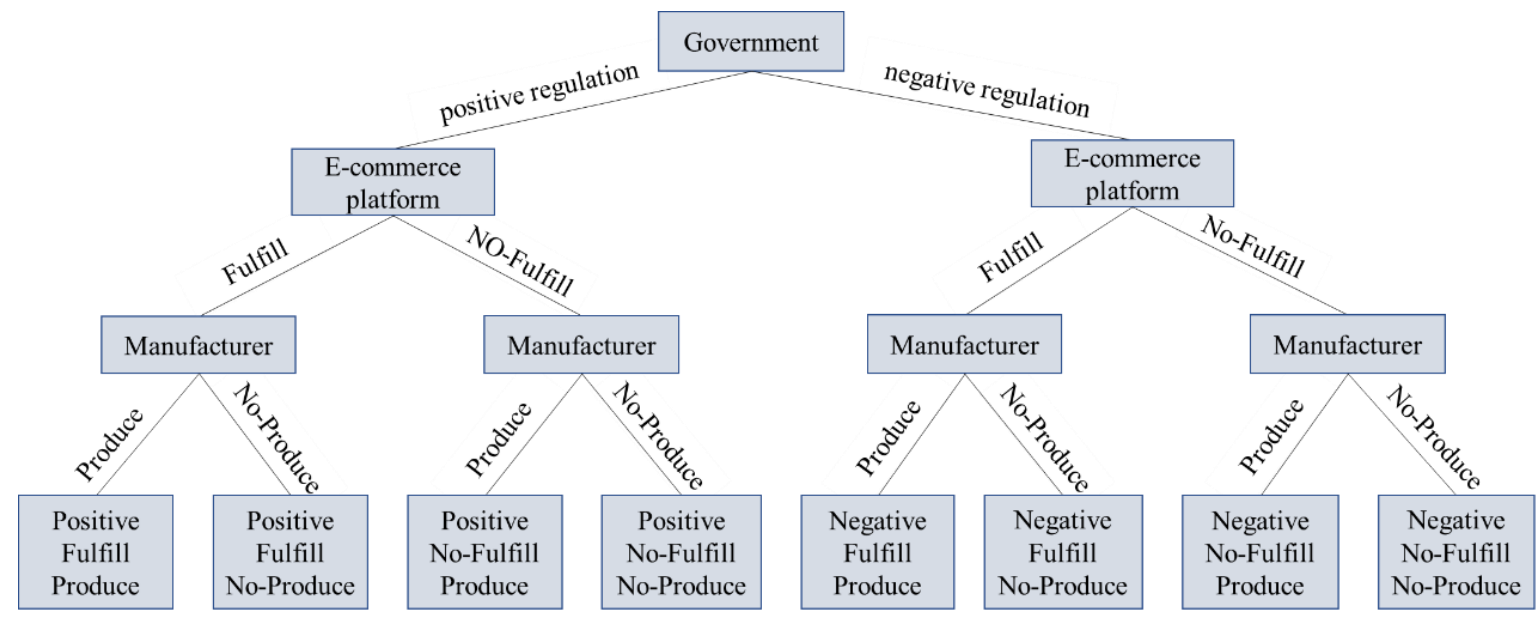

Figure 1. The Tripartite Game Tree 


\section{2 payoff matrix}

According to Figure 1, the payoff matrix of the government, food manufacturer and e-commerce retailer is shown in Table 2.

Table 2 Payoff matrix

\begin{tabular}{|c|c|c|c|c|}
\hline & \multirow{2}{*}{\multicolumn{2}{|c|}{$\underline{\text { Strategy }}$}} & \multicolumn{2}{|c|}{ Manufactures } \\
\hline & & & Produce (y) & No- Produce (1-y) \\
\hline \multirow{4}{*}{ Government } & \multirow{2}{*}{$\begin{array}{l}\text { Positive } \\
\text { Regulation } \\
\text { (z) }\end{array}$} & $\begin{array}{c}\text { E-commerce } \\
\text { retailers } \\
\text { Fulfill (x) }\end{array}$ & $\begin{array}{c}\gamma N-\eta I_{1}-\xi I_{2} \\
(1+\alpha) \pi_{1}-C_{1}+\eta I_{1} \\
(1+\beta) \pi_{2}-C_{2}+\xi I_{2}-\gamma N\end{array}$ & $\begin{array}{c}\omega Q-\eta I_{1} \\
(1+\alpha) \pi_{1}-C_{1}+\eta I_{1} \\
\pi_{2}+\mathrm{T}_{2}-\omega Q\end{array}$ \\
\hline & & $\begin{array}{l}\text { E-commerce } \\
\text { retailers } \\
\text { No- Fulfill } \\
\quad(1-\mathrm{x})\end{array}$ & $\begin{array}{c}\gamma N+\lambda P-\xi I_{2} \\
\pi_{1}+\mathrm{T}_{1}-\lambda P \\
(1+\beta) \pi_{2}-C_{2}+\xi I_{2}-\gamma N\end{array}$ & $\begin{array}{l}\lambda P+\omega Q \\
\pi_{1}-\lambda P \\
\pi_{2}-\omega Q\end{array}$ \\
\hline & \multirow{2}{*}{$\begin{array}{c}\text { Negative } \\
\text { Regulation } \\
\quad(1-z)\end{array}$} & $\begin{array}{c}\text { E-commerce } \\
\text { retailers } \\
\text { Fulfill (x) }\end{array}$ & $\begin{array}{c}-\xi I_{2} \\
(1+\alpha) \pi_{1}-C_{1} \\
(1+\beta) \pi_{2}-C_{2}+\xi I_{2}\end{array}$ & $\begin{array}{c}0 \\
(1+\alpha) \pi_{1}-C_{1} \\
\pi_{2}+\mathrm{T}_{2}\end{array}$ \\
\hline & & $\begin{array}{l}\text { E-commerce } \\
\text { retailers } \\
\text { No- Fulfill } \\
\quad(1-\mathrm{x})\end{array}$ & $\begin{array}{c}-\xi I_{2} \\
\pi_{1}+\mathrm{T}_{1} \\
(1+\beta) \pi_{2}-C_{2}+\xi I_{2}\end{array}$ & $\begin{array}{l}0 \\
\pi_{1} \\
\pi_{2}\end{array}$ \\
\hline
\end{tabular}

\section{Equilibrium analysis of evolutionary game}

\subsection{Revenue function}

According to the payoff matrix in Table 1, the expected revenue for each of the three parties can be obtained as follows:

(1) The expected revenue of the e-commerce retailer when it chooses the responsibility fulfillment strategy is $U_{11}$, the expected revenue when it chooses the non-fulfillment responsibility strategy is $U_{12}$, and the average expected revenue of the e-commerce retailer is $\bar{U}_{1}$. The expressions of these three indicators are as follows:

$$
\begin{aligned}
& U_{11}=y z\left[(1+\alpha) \pi_{1}-C_{1}+\eta I_{1}\right]+y(1-z)\left[(1+\alpha) \pi_{1}-C_{1}\right]+ \\
& \quad z(1-y)\left[(1+\alpha) \pi_{1}-C_{1}+\eta I_{1}\right]+(1-y)(1-z)\left[(1+\alpha) \pi_{1}-C_{1}\right] \\
& U_{12}=y z\left(\pi_{1}+T_{1}-\lambda P\right)+y(1-z)\left(\pi_{1}+T_{1}\right)+z(1-y)\left(\pi_{1}-\lambda P\right)+(1-y)(1-z) \pi_{1} \\
& \overline{U_{1}}=x U_{11}+(1-x) U_{12}=\pi_{1}-x C_{1}+y T_{1}+\alpha x \pi_{1}-z \lambda P-x y T_{1}+x z \eta I_{1}+x z \lambda P
\end{aligned}
$$


(2) The expected revenue of the manufacturer when it chooses to produce organic food strategy is $U_{21}$, the expected revenue when the manufacturer chooses the non-organic production strategy is $U_{22}$, and the average expected revenue of the manufacturer is $\bar{U}_{2}$. The expressions of these three indicators are as follows:

$$
\begin{aligned}
U_{21}= & x z\left[(1+\beta) \pi_{2}-C_{2}+\xi I_{2}-\gamma N\right]+x(1-z)\left[(1+\beta) \pi_{2}-C_{2}+\xi I_{2}\right]+ \\
& z(1-x)\left[(1+\beta) \pi_{2}-C_{2}+\xi I_{2}-\gamma N\right]+(1-x)(1-z)\left[(1+\beta) \pi_{2}-C_{2}+\xi I_{2}\right] \\
U_{22}= & x z\left(\pi_{2}+\mathrm{T}_{2}-\omega Q\right)+x(1-z)\left(\pi_{2}+\mathrm{T}_{2}\right)+z(1-x)\left(\pi_{2}-\omega Q\right)+(1-x)(1-z) \pi_{2} \\
\overline{U_{2}}= & y U_{21}+(1-y) U_{22}=\pi_{2}-y C_{2}+x T_{2}+\xi y I_{2}+\beta y \pi_{2}-z \omega Q-x y T_{2}
\end{aligned}
$$

(3) The expected revenue of the government when it chooses the positive regulation strategy is $U_{31}$, the expected revenue when the government chooses the negative regulation strategy is $U_{32}$, and the average expected revenue of the government is $\bar{U}_{3}$. The expressions of these three indicators are as follows:

$$
\begin{aligned}
U_{31}= & x y\left(\gamma N-\eta I_{1}-\xi I_{2}\right)+x(1-y)\left(\omega \mathrm{Q}-\eta \mathrm{I}_{1}\right)+y(1-x)\left(\gamma N+\lambda P-\xi I_{2}\right) \\
& +(1-x)(1-y)(\lambda P+\omega Q) \\
U_{32}= & x y\left(-\xi I_{2}\right)+y(1-x)\left(-\xi I_{2}\right) \\
\overline{U_{3}}= & z U_{31}+(1-z) U_{32}=z \lambda P-y \xi I_{2}+z \omega Q-x z \eta I_{1}+y z \gamma N-x z \lambda P-y z \omega Q
\end{aligned}
$$

\subsection{Three-party game replicator dynamic equations}

The replicator dynamic equation of the e-commerce retailer's choice of fulfillment strategy is

$$
F_{1}(x)=\frac{d x}{d t}=x\left(U_{11}-\overline{U_{1}}\right)=-x(x-1)\left(\alpha \pi_{1}-C_{1}-y T_{1}+\eta z I_{1}+z \lambda P\right)
$$

The replicator dynamic equation of the manufacturer's choice of producing organic food strategy is

$$
F_{2}(x)=\frac{d y}{d t}=y\left(U_{21}-\overline{U_{2}}\right)=y(y-1)\left(C_{2}-\xi I_{2}-\beta \pi_{2}-z \omega Q+x T_{2}+z \gamma N\right)
$$

The replicator dynamic equation of the government's choice of positive regulation strategy is

$$
F_{3}(x)=\frac{d z}{d t}=z\left(U_{31}-\overline{U_{3}}\right)=-z(z-1)\left(\lambda P+\omega Q-x \eta I_{1}+y \gamma N-x \lambda P-y \omega Q\right)
$$

\subsection{Stability analysis of evolutionary game}

Let the replicator dynamic equation $\left\{\begin{array}{l}F_{1}(x)=0 \\ F_{2}(y)=0 \\ F_{3}(z)=0\end{array}\right.$, we can get 14 equilibrium points on 
$\{(x, y, z) \mid 0 \leq x \leq 1,0 \leq y \leq 1,0 \leq z \leq 1\}$, which are:

$$
\begin{aligned}
& \left(\frac{\lambda P+\gamma N}{\eta I_{1}+\lambda P}, 1, \frac{C_{1}+T_{1}-\alpha \pi_{1}}{\eta I_{1}+\lambda P}\right),\left(1, \frac{\eta I_{1}-\omega Q}{\gamma N-\omega Q}, \frac{C_{2}+T_{2}-\xi I_{2}-\beta \pi_{2}}{\omega Q-\gamma N}\right),\left(0, \frac{-(\lambda P+\omega Q)}{\gamma N-\omega Q}, \frac{\xi I_{2}-C_{2}+\beta \pi_{2}}{\gamma N-\omega Q}\right), \\
& \left(\frac{\xi I_{2}-C_{2}+\beta \pi_{2}-\gamma N+\omega Q}{T_{2}}, \frac{\alpha \pi_{1}-C_{1}+\eta I_{1}+\lambda P}{T_{1}}, 1\right), \\
& \left(\frac{\xi I_{2}-C_{2}+\beta \pi_{2}}{T_{2}}, \frac{\alpha \pi_{1}-C_{1}}{T_{1}}, 0\right),\left(\mathrm{x}^{*}, \mathrm{y}^{*}, \mathrm{z}^{*}\right),(0,0,0),(1,0,0),(0,1,0),(0,0,1),(1,1,0),(1,0,1),
\end{aligned}
$$

$(0,1,1),(1,1,1)$.

Among them:

$$
\begin{aligned}
x^{*}= & \left(\omega Q C_{1}-\gamma N C_{1}-\lambda P C_{2}-\eta I_{1} C_{2}+\lambda P T_{1}+\omega Q T_{1}+\eta \xi I_{1} I_{2}+\eta \beta I_{1} \pi_{2}+\alpha \gamma N \pi_{1}+\xi \lambda P I_{2}+\right. \\
& \left.\beta \lambda P \pi_{2}-\alpha \omega Q \pi_{1}\right) /\left(T_{1}+T_{2}\right)\left(\eta I_{1}+\lambda P\right) \\
y^{*}= & -\left(\eta C_{2} I_{1}+\gamma N C_{1}+\lambda P C_{2}-\omega Q C_{1}+\lambda P T_{2}+\omega Q T_{2}-\eta \xi I_{1} I_{2}-\eta \beta I_{1} \pi_{2}-\alpha \gamma N \pi_{1}-\xi \lambda P I_{2}\right. \\
& \left.-\beta \lambda P \pi_{2}+\alpha \omega Q \pi_{1}\right) /\left(T_{1}+T_{2}\right)(\gamma N-\omega Q) \\
z^{*}= & -\left(\eta C_{2} I_{1} T_{1}-\gamma C_{1} N T_{2}+\lambda P T_{1} C_{2}+\omega Q T_{2} C_{1}+\lambda P T_{1} T_{2}+\omega Q T_{1} T_{2}-\xi \eta T_{1} I_{2} I_{2}-\beta \eta T_{1} I_{1} \pi_{2}\right. \\
& \left.+\alpha \gamma N T_{2} \pi_{1}-\lambda \xi P T_{1} I_{2}-\beta \lambda P T_{1} \pi_{2}-\alpha \omega Q T_{2} \pi_{1}\right) /\left(T_{1}+T_{2}\right)\left(\eta I_{1}+\lambda P\right)(\gamma N-\omega Q)
\end{aligned}
$$

In asymmetric games, if the equilibrium point of evolutionary game is an evolutionary stable equilibrium, then it must be a strict Nash equilibrium and a pure strategic equilibrium, so mixed strategy equilibrium must not be an evolutionary stable equilibrium. Therefore, we only need to discuss the asymptotic stability of pure strategy equilibrium. Hence, this paper only analyzes the asymptotic stability of the system at the eight points $(0,0,0),(1,0,0),(0,1$, $0),(0,0,1),(1,1,0),(1,0,1),(0,1,1),(1,1,1)$.

According to the evolutionary game theory, when $F_{1}{ }^{\prime}(x)<0, F_{2}{ }^{\prime}(y)<0, F_{3}{ }^{\prime}(z)<0$, the evolution and stability strategies of the e-commerce retailer, the food manufacturer and the government in the evolution process are:

$$
\begin{aligned}
& F_{1}^{\prime}(x)=\frac{\partial F(x)}{x}=-(2 x-1)\left(\alpha \pi_{1}-C_{1}-y T_{1}+\eta z I_{1}+z \lambda P\right) \\
& F_{2}^{\prime}(y)=\frac{\partial F(y)}{y}=(2 y-1)\left(C_{2}-\xi I_{2}-\beta \pi_{2}-z \omega Q+x T_{2}+z \gamma N\right) \\
& F_{3}^{\prime}(z)=\frac{\partial F(z)}{z}=-(2 z-1)\left(\lambda P+\omega Q-x \eta I_{1}+y \gamma N-x \lambda P-y \omega Q\right)
\end{aligned}
$$

\subsubsection{Analysis of asymptotic stability of the e-commerce retailer}

(1) According to equation (13), if $\alpha \pi_{1}-C_{1}-y T_{1}+\eta z I_{1}+z \lambda P=0$, then $F_{1}(x)=0$. This is the boundary of evolutionary stability; both the left and right levels are in a stable state at this time, and the strategy choice will not change with time.

(2) If $\alpha \pi_{1}-C_{1}-y T_{1}+\eta z I_{1}+z \lambda P>0$, Let $F_{1}(x)=0$, we can find $x=0$ or $x=1$ is the evolutionary stable points, from the formula $F_{1}^{\prime}(x)=-(2 x-1)\left(\alpha \pi_{1}-C_{1}-y T_{1}+\eta z I_{1}+z \lambda P\right)$, we get $F^{\prime}(0)>0, F^{\prime}(1)<0$, so $x=1$ is the stable point. This indicates that the excess income obtained by the e-commerce retailer when it chooses to fulfill its responsibilities (deduct its obligation cost and add to the potential government funding) is greater than the potential gain when it chooses not to fulfill its responsibilities, then fulfills its social responsibility is the evolutionary 
stability strategy adopted by the e-commerce retailers.

(3) If $\alpha \pi_{1}-C_{1}-y T_{1}+\eta z I_{1}+z \lambda P<0$, Let $F_{1}(x)=0$, we can find $x=0$ or $x=1$ is the evolutionary stable points, from the formula $F_{1}{ }^{\prime}(x)=-(2 x-1)\left(\alpha \pi_{1}-C_{1}-y T_{1}+\eta z I_{1}+z \lambda P\right)$, we get $F^{\prime}(0)<0, F^{\prime}(1)>0$, so $x=0$ is the stable point. This indicates that the excess income obtained by the e-commerce retailer when it chooses to fulfill its responsibilities (deduct its obligation cost and add to the potential government funding) is less than the potential gain when it chooses not to fulfill its responsibilities, then not fulfilling its social responsibilities is the evolutionary stability strategy adopted by the e-commerce retailer.

\subsubsection{Analysis of asymptotic stability of the manufacturer}

(1) According to equation (14), if $C_{2}-\xi I_{2}-\beta \pi_{2}-z \omega Q+x T_{2}+z \gamma N=0$, then $F_{2}(y)=0$. This is the boundary of evolutionary stability. Both the left and right levels are in a stable state at this time, and the strategy choice will not change with time.

(2) If $C_{2}-\xi I_{2}-\beta \pi_{2}-z \omega Q+x T_{2}+z \gamma N>0$, Let $F_{2}(y)=0$, we can find $x=0$ or $x=1$ is the evolutionary stable points, from the formula $F_{2}^{\prime}(y)=(2 y-1)\left(C_{2}-\xi I_{2}-\beta \pi_{2}-z \omega Q+x T_{2}+z \gamma N\right)$, we get $F^{\prime}(0)<0, F^{\prime}(1)>0$, so $x=0$ is the stable point. This indicates that the excess earning obtained by the manufacturer when it chooses to produce organic food is less than the potential gain when it chooses not to produce organic food, then the non-production of organic food is the evolutionary stability strategy adopted by the manufacturer.

(3) If $C_{2}-\xi I_{2}-\beta \pi_{2}-z \omega Q+x T_{2}+z \gamma N<0$, Let $F_{2}(y)=0$, we can find $x=0$ or $x=1$ is the evolutionary stable points, from the formula $F_{2}^{\prime}(y)=(2 y-1)\left(C_{2}-\xi I_{2}-\beta \pi_{2}-z \omega Q+x T_{2}+z \gamma N\right)$, we get $F^{\prime}(0)<0, F^{\prime}(1)>0$, so $x=1$ is the stable point. This shows that the excess earning obtained by the manufacturer when it chooses to produce organic food is greater than the potential gain when it chooses not to produce organic food, then the production of organic food is the evolutionary stability strategy adopted by the manufacturer .

\subsubsection{Analysis of asymptotic stability of government}

(1) According to equation (15), if $\lambda P+\omega Q-x \eta I_{1}+y \gamma N-x \lambda P-y \omega Q=0$, then $F_{3}(z)=0$. This is the boundary of evolutionary stability, where both the left and right levels are in a stable state at this time, and the strategy choice will not change with time.

(2) If $\lambda P+\omega Q-x \eta I_{1}+y \gamma N-x \lambda P-y \omega Q>0$, Let $F_{3}(z)=0$, we can get $x=0$ or $x=1$ is the evolutionary stable points, from the formula

$F_{3}^{\prime}(z)=-(2 z-1)\left(\lambda P+\omega Q-x \eta I_{1}+y \gamma N-x \lambda P-y \omega Q\right)$, we get $F^{\prime}(0)>0, F^{\prime}(1)<0$, so $x=0$ is the stable point. Therefore, active regulation is the evolutionary stability strategy adopted by the government.

(3) If $\lambda P+\omega Q-x \eta I_{1}+y \gamma N-x \lambda P-y \omega Q<0$, Let $F_{3}(z)=0$, we can get $x=0$ or $x=1$ is the stable points, from the formula $F_{3}{ }^{\prime}(z)=-(2 z-1)\left(\lambda P+\omega Q-x \eta I_{1}+y \gamma N-x \lambda P-y \omega Q\right)$, we get $F^{\prime}(0)<0, F^{\prime}(1)>0$, so $x=1$ is the stable point, Therefore, negative regulation is the evolutionary stability strategy the government.

\section{Analysis of evolutionary stability strategy}

It can be seen from the analysis of the evolutionary stability of each party of the game above that, during the game process, the evolutionary equilibrium state of the decision-making 
of any party changes with the change of the proportion of the other two parties choosing positive strategies in the evolutionary process. Because the ratio of $\mathrm{x}, \mathrm{y}, \mathrm{z}$ of the e-commerce retailer, manufacturer and government to choose positive strategies is constantly changing in the evolutionary process. At the same time, the evolutionary equilibrium of game system for small perturbations of $\mathrm{x}, \mathrm{y}, \mathrm{z}$ also does not have robustness. Therefore, the evolution of the tripartite game to each expected steady state cannot be promoted simply by adjusting the initial conditions. This paper focuses on the promotion mechanism of social responsibility in the organic food supply chain. By promoting all parties in the game, it eventually evolves into the ideal state $(1,1,1)$ of "responsibility fulfillment" by the e-commerce retailers, "production" by the manufacturer, and "active regulation" by the government. Therefore, relevant variables can be adjusted or controlled to guide the behavior of each party to evolve in the ideal direction.

According to the evolutionary stability analysis above, when $z>\frac{-\alpha \pi_{1}+C_{1}+y T_{1}}{\eta I_{1}+\lambda P}, x \rightarrow 1$, the e-commerce retailers tend to choose responsibility fulfillment strategies. When $z>\frac{C_{2}-\xi I_{2}-\beta \pi_{2}+x T_{2}}{\omega Q-\gamma N}, y \rightarrow 1$, the manufacturer tends to choose to produce organic food. Therefore, if we increase the government support $\eta$ for the e-commerce retailers, the subsidies $\xi$ for manufacturer, the fine $\lambda$ for the e-commerce retailer not fulfilling its responsibilities and the penalty $\omega$ for the manufacturer not producing organic products, these regulation policies are conducive to the evolution of the e-commerce retailers and the manufacturer towards the positive strategy.

The group evolution of e-commerce retailers, the manufacturer and governments can be described according to the differential equation, but it is not clear to which equilibrium point the system will evolve. The following is the analysis of the local stability of the system at each equilibrium point according to the Jacobian analysis matrix:

$$
J=\left(\begin{array}{ccc}
\frac{\partial F(x)}{x} & \frac{\partial F(x)}{y} & \frac{\partial F(x)}{z} \\
\frac{\partial F(y)}{x} & \frac{\partial F(y)}{y} & \frac{\partial F(y)}{z} \\
\frac{\partial F(z)}{x} & \frac{\partial F(z)}{y} & \frac{\partial F(z)}{z}
\end{array}\right)
$$

Among them:

$$
\begin{aligned}
& \frac{\partial F(x)}{x}=-(2 x-1)\left(\alpha \pi_{1}-C_{1}-y T_{1}+z \eta I_{1}+z \lambda P\right) \\
& \frac{\partial F(y)}{x}=y(y-1) T \\
& \frac{\partial F(z)}{x}=z(z-1)\left(\eta I_{1}+\lambda P\right) \\
& \frac{\partial F(x)}{y}=x(x-1) T \\
& \frac{\partial F(y)}{y}=(2 y-1)\left(C_{2}-\xi I_{2}-\beta \pi_{2}+x T_{2}+z \lambda N-z \omega Q\right)
\end{aligned}
$$




$$
\begin{aligned}
& \frac{\partial F(z)}{y}=-z(z-1)(\gamma N-\omega Q) \\
& \frac{\partial F(x)}{z}=-x(x-1)\left(\eta I_{1}+\lambda P\right) \\
& \frac{\partial F(y)}{z}=y(y-1)(\gamma N-\omega Q) \\
& \frac{\partial F(z)}{z}=-(2 z-1)\left(\lambda P+\omega Q-x \eta I_{1}+\gamma y N-x \lambda P-y \omega Q\right)
\end{aligned}
$$

Based on the above analysis, the system has eight special equilibrium points, which are $(0,0,0),(0,0,1),(0,1,0),(0,1,1),(1,0,0),(1,0,1),(1,1,0),(1,1,1)$. According to the evolutionary game theory, the equilibrium point when all the eigenvalues of the Jacobian matrix are non-positive is the asymptotic stability point of the system. The stability of the system is discussed by taking $(0,0,0)$ as an example, so the Jacobian matrix of the system at $(0,0,0)$ is:

$$
J=\left(\begin{array}{ccc}
\alpha \pi_{1}-C_{1} & 0 & 0 \\
0 & \beta \pi_{2}-C_{2}+\xi I_{2} & 0 \\
0 & 0 & \lambda P+\omega Q
\end{array}\right)
$$

Therefore, the eigenvalues are $\lambda_{1}=\alpha \pi_{1}-C_{1}, \quad \lambda_{2}=\beta \pi_{2}-C_{2}+\xi I_{2}, \quad \lambda_{3}=\lambda P+\omega Q$. The

\begin{tabular}{|c|c|c|}
\hline Equilibrium point & Eigenvalue & Stability \\
\hline$(\mathbf{0}, \mathbf{0}, \mathbf{0})$ & $\begin{array}{l}\lambda_{1}=\alpha \pi_{1}-C_{1}>0 \\
\lambda_{2}=\beta \pi_{2}-C_{2}+\xi I_{2}>0 \\
\lambda_{3}=\lambda P+\omega Q>0\end{array}$ & Instability point \\
\hline$(0,0,1)$ & $\begin{array}{l}\lambda_{1}=\alpha \pi_{1}-C_{1}+\eta I_{1}+\lambda P>0 \\
\lambda_{2}=\beta \pi_{2}-C_{2}+\xi I_{2}-\gamma N+\omega Q \\
\lambda_{3}=-\lambda P-\omega Q<0\end{array}$ & Saddle point \\
\hline$(0,1,0)$ & $\begin{array}{l}\lambda_{1}=\alpha \pi_{1}-C_{1}-T_{1} \\
\lambda_{2}=-\beta \pi_{2}+C_{2}-\xi I_{2}<0 \\
\lambda_{3}=\lambda P+\gamma N>0\end{array}$ & Saddle point \\
\hline$(0,1,1)$ & $\begin{array}{l}\lambda_{1}=\alpha \pi_{1}-C_{1}-T_{1}+\eta I_{1}+\lambda P \\
\lambda_{2}=-\beta \pi_{2}+C_{2}-\xi I_{2}+\gamma N-\omega Q<0 \\
\lambda_{3}=-\lambda P-\gamma N<0\end{array}$ & $\begin{array}{c}\alpha \pi_{1}-C_{1}-T_{1}+\eta I_{1}+\lambda P<0 \\
\text { asymptotic stability point } \\
\alpha \pi_{1}-C_{1}-T_{1}+\eta I_{1}+\lambda P>0 \\
\text { Saddle point }\end{array}$ \\
\hline$(1,0,0)$ & $\begin{array}{l}\lambda_{1}=C_{1}-\alpha \pi_{1}<0 \\
\lambda_{2}=\beta \pi_{2}-C_{2}-T_{2}+\xi I_{2} \\
\lambda_{3}=\omega Q-\eta I_{1}>0\end{array}$ & Saddle point \\
\hline$(1,0,1)$ & $\begin{array}{l}\lambda_{1}=C_{1}-\alpha \pi_{1}-\eta I_{1}-\lambda P<0 \\
\lambda_{2}=\beta \pi_{2}-C_{2}-T_{2}+\xi I_{2}-\gamma N+\omega Q \\
\lambda_{3}=\eta I_{1}-\omega Q<0\end{array}$ & $\begin{array}{c}\beta \pi_{2}-C_{2}-T_{2}+\xi I_{2}-\gamma N+\omega Q<0 \\
\text { asymptotic stability point } \\
\beta \pi_{2}-C_{2}-T_{2}+\xi I_{2}-\gamma N+\omega Q>0 \\
\text { Saddle point }\end{array}$ \\
\hline
\end{tabular}
eigenvalues of the Jacobian matrix correspond to other equilibrium points and stability analysis of each equilibrium point can be obtained as shown in Table 3:

Table 3 Stability analysis of Jacobian matrix of each equilibrium point

\section{Equilibrium point}




\begin{tabular}{c|l|c}
\hline \multirow{4}{*}{$(\mathbf{1}, \mathbf{1}, \mathbf{0})$} & $\lambda_{1}=C_{1}-\alpha \pi_{1}+T_{1}$ & \\
& $\lambda_{2}=-\beta \pi_{2}+C_{2}+T_{2}-\xi I_{2}$ & Saddle point \\
& $\lambda_{3}=\gamma N-\eta I_{1}>0$ & \\
\hline \multirow{3}{*}{$(\mathbf{1}, \mathbf{1}, \mathbf{1})$} & $\lambda_{1}=C_{1}+T_{1}-\alpha \pi_{1}-\eta I_{1}-\lambda P$ & $\alpha \pi_{1}-C_{1}-T_{1}+\eta I_{1}+\lambda P>0$ and \\
& $\lambda_{2}=C_{2}+T_{2}-\xi I_{2}-\beta \pi_{2}+\gamma N-\omega Q$ & $\beta \pi_{2}-C_{2}-T_{2}+\xi I_{2}-\gamma N+\omega Q>0$ \\
& $\lambda_{3}=\eta I_{1}-\gamma N<0$ & asymptotic stability point \\
\hline
\end{tabular}

As shown in Table 3, the evolution of behavioral strategies of participants in the organic food supply chain is influenced by many factors. It can be seen from the stability analysis of equilibrium points shown in the table that when $\alpha \pi_{1}-C_{1}-T_{1}+\eta I_{1}+\lambda P<0$ the evolutionary stability strategy of e-commerce retailers is not to fulfill their social responsibilities. At this point $(0,1,1)$ is the evolutionary stability equilibrium point of the system. However, if $\beta \pi_{2}-C_{2}-T_{2}+\xi I_{2}-\gamma N+\omega Q<0$, the organic manufacturer will evolve to the trend of no production, so this point $(1,0,1)$ is the stable evolutionary equilibrium point of the system. But if $\alpha \pi_{1}-C_{1}-T_{1}+\eta I_{1}+\lambda P>0$ and $\beta \pi_{2}-C_{2}-T_{2}+\xi I_{2}-\gamma N+\omega Q>0$, the three-party system will eventually evolve to the optimal state, and the system tends to the asymptotic stability point of $(1,1,1)$.

\section{Simulation analysis}

In order to verify the validity of the established model and its conclusions, we further study the influence of relevant parameters on the evolutionary game, and discuss the evolutionary game process of each participant in the game under government regulation. This paper conducts numerical simulation and simulation analysis based on Matlab.

First, let us assume parameters $\pi_{1}=0.4, \pi_{2}=0.9, \alpha=0.4, \beta=0.6, C_{1}=0.15, C_{2}=0.4, T_{1}=0.1$, $T_{2}=0.2, I_{1}=0.1, \xi=0.5, I_{2}=0.2, N=0.15, \omega=0.5, Q=0.15, P=0.15$. The values of the parameters are set according to the conditions obtained by the model solution.

Simulation analysis is carried out according to the above assumptions. Simulation results are shown in Figure 2:

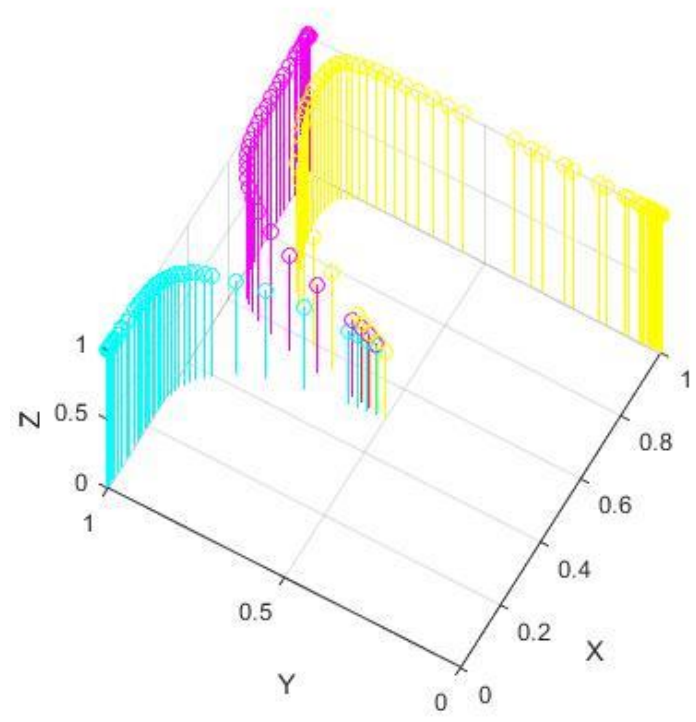

Figure 2 Evolution trend chart of "government-e-commerce retailer-manufacturer" 
As shown in Figure 2, the stability of each condition equilibrium point of the Jacobian matrix is verified. We can find that e-commerce retailers will choose to fulfill their responsibilities when the excess earnings obtained from fulfilling their responsibilities are greater than the potential earnings gained from choosing not to fulfill their responsibilities. In this case, e-commerce retailers will supervise and control the quality and safety of organic food sold on their platforms. When the excess profits of producing organic food are greater than the potential profits of not producing organic food, the manufacturer will choose to produce organic food.

In order to analyze the government regulation for organic food supply chain evolution behavior and the effect of different parties, the following is the analysis of the government's funding intensity $\eta$ to e-commerce retailers for fulfilling responsibility, the fine intensity $\lambda$ to e-commerce retailers for failing to fulfill their responsibility, the subsidy intensity $\xi$ to the manufacturer for producing organic food, the penalty intensity $\omega$ to the manufacturer for nonorganic production, and the supervision intensity $\gamma$ to the manufacturer for fraudulent subsidies claiming behavior and other parameters' influence on the evolutionary behavior of game players.

\subsection{The influence of the government's funding to e-commerce retailers on the evolution behavior of the tripartite game}

$\eta$ takes the values of $0.1,0.5$ and 0.9 respectively, indicating that the government provides low-intensity, medium-intensity and high-intensity funding to e-commerce retailers that fulfill their responsibility. Then, the evolution trend of each party of the game is as follows:

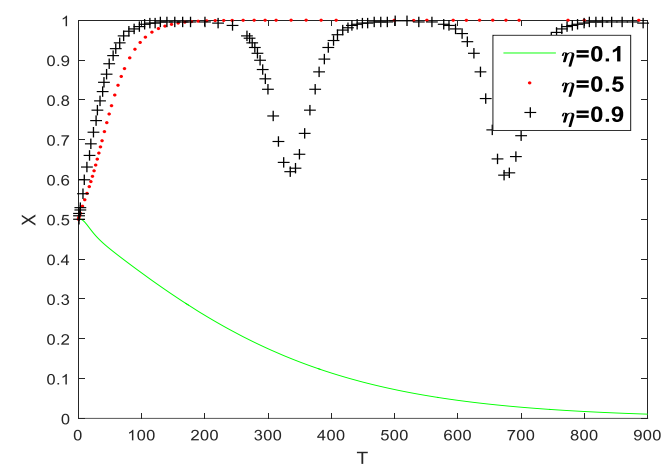

Figure 3 Evolution trend of the behavior of e-commerce retailers under different funding levels

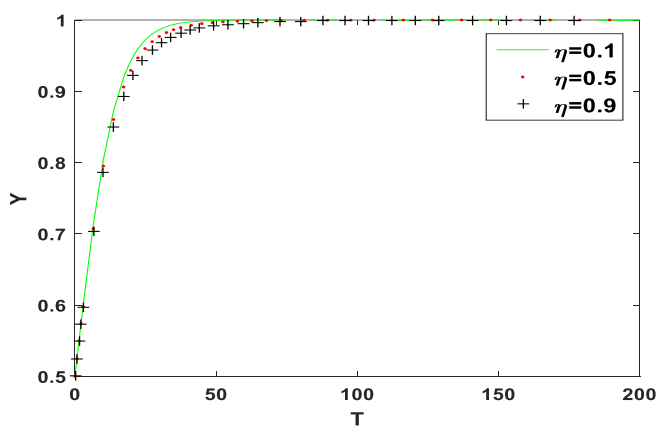

Figure 4 Evolution trend of the behavior of manufacturers under different funding levels 


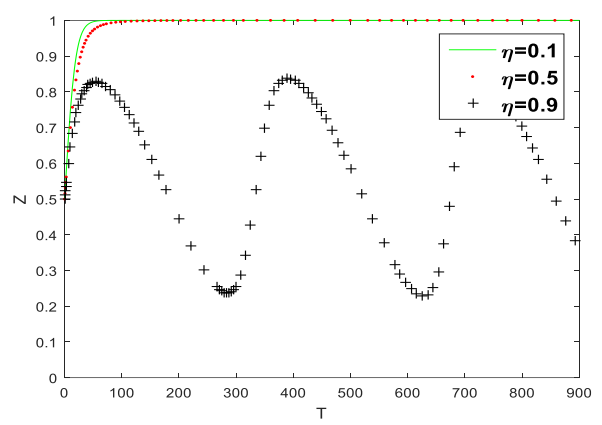

Figure 5 Evolution trend of government regulation under different funding levels

The change of the e-Commerce retailers' strategies over time is shown in Figure 3. When the government funding intensity for e-commerce retailers is low, the e-commerce retailers will choose the "no fulfillment" strategy. With the improvement of government assistance, when the government funding to a certain extent makes up for the cost of e-commerce retailers' supervision on organic food quality and safety, e-commerce retailers will evolve towards the choice of fulfilling their responsibilities. But when the government gives high-intensity funding to e-commerce retailers, the active supervision of e-commerce retailers promotes the continuous maturity of the organic food market; in this case, the government will choose to reduce funding intensity for e-commerce retailers, which will lead to the probability that the number of e-commerce retailers that choose to fulfill their responsibilities gradually falls. In such situation, the system has no evolutionary stable state.

The change of the manufacturer strategies over time is shown in Figure 4. With the increase of government funding to e-commerce retailers, the probability of e-commerce retailers fulfilling their social responsibilities has increased, and they begin to actively supervise the quality of products, so as to ensure the quality of organic food sold on e-commerce retailers, thus driving manufacturers to improve their social responsibility.

The change of government regulations over time is shown in Figure 5. As can be seen from the figure, the government's moderate funding to e-commerce retailers helps promote the latter to fulfill their responsibilities. However, high-intensity funding will increase the dependence of e-commerce retailers on government funding and fail to achieve the effect of active government regulation. This also suggests that the regulation of the organic food supply chain by the government should not only rely on the means of funding e-commerce retailers, but also be combined with other means such as punishment strategy to achieve the effect of active regulation.

\subsection{The influence of the government's fine for e-commerce retailers on the evolution behavior}

\section{of the tripartite game}

$\lambda$ takes the values of $0.1,0.5$ and 0.9 , respectively, indicating that the government provides low-intensity, medium-intensity and high-intensity fine for e-commerce retailers that do not fulfill their responsibility; then the evolution trend of each subject of the game is as follows: 


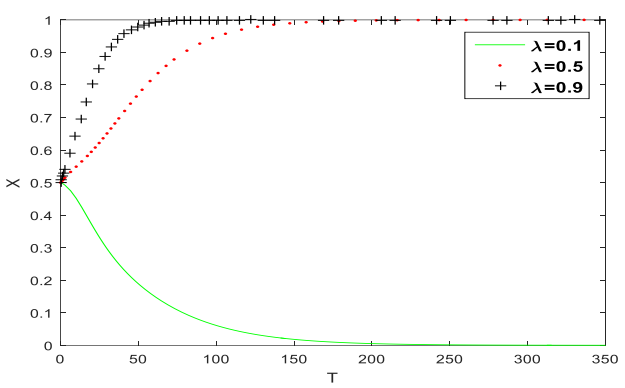

Figure 6 Evolution trend of the behavior of e-commerce retailers under different fine levels

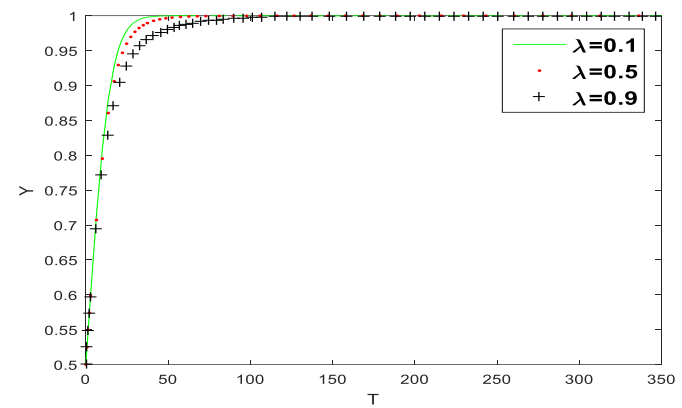

Figure 7 Evolution trend of the behavior of manufacturer under different fine levels

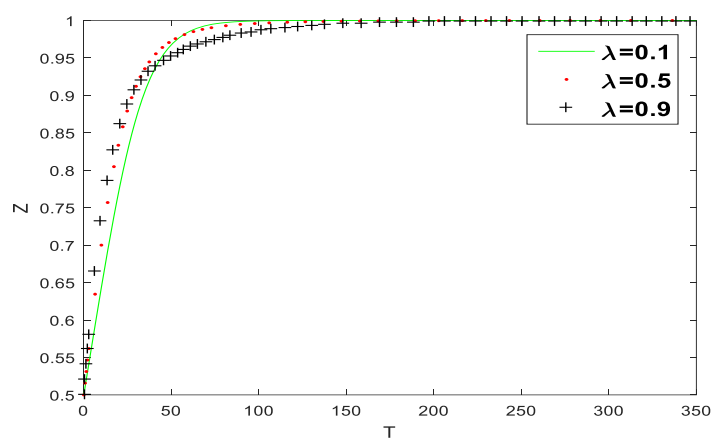

Figure 8 Evolution trend of government regulation under different fine levels

Figure 6 shows how e-commerce retailers' strategies change over time. When the fine is low, e-commerce retailers will choose not to take responsibility of strategy. At present Chinese enterprises lack social responsibility consciousness; at the same time, consumers' awareness of rights protection is weak and they do not know much about the organic food. Although failure to fulfill their responsibilities may be punished, e-commerce retailers will still choose the strategy of failing to fulfill their responsibilities as the fine is relatively low. When the fine intensity increases, e-commerce retailers will tend to fulfill their responsibility due to high fine costs. Therefore, the government should increase the fine to e-commerce retailers for not fulfilling their responsibilities, so as to improve their awareness of the need to do so.

The change of the manufacturer's strategies over time is shown in Figure 7. No matter how severely the government punishes e-commerce retailers for not fulfilling their responsibilities, it will promote the manufacturer that evolve towards the choice of produce organic food. However, as the government fine for e-commerce retailers that failed to fulfill their responsibilities increased, the slower the manufacturer evolved towards the choice to produce 
organic food. The main reason is that to respond to the government's high fine for not fulfilling their responsibilities, e-commerce retailers will put forward high requirements for the organic food sold on the platform, thereby increasing the production organizations' difficulty of the manufacturer. In order to avoid higher operational risks, the rate of evolution of the manufacturer to actively produce organic food has slowed down.

The change of government regulation over time is shown in Figure 8. It can be seen from the figure that, at the beginning, the stronger the government punishes e-commerce retailers, the faster the government evolves to active regulation. In this process, the degree of e-commerce responsibilities to fulfill gradually increases. At this time, as the government fine for ecommerce retailers increases, the time from the strategy selection of government to the equilibrium state gradually increases.

\subsection{The influence of the government's subsidy for manufacturer on the evolution behavior of}

\section{the tripartite game}

$\xi$ takes the values of $0.1,0.5$ and 0.9 , respectively, indicating that the government provides low-intensity, medium-intensity and high-intensity subsidy for manufacturers, and then the evolution trend of each subject of the game is as follows:

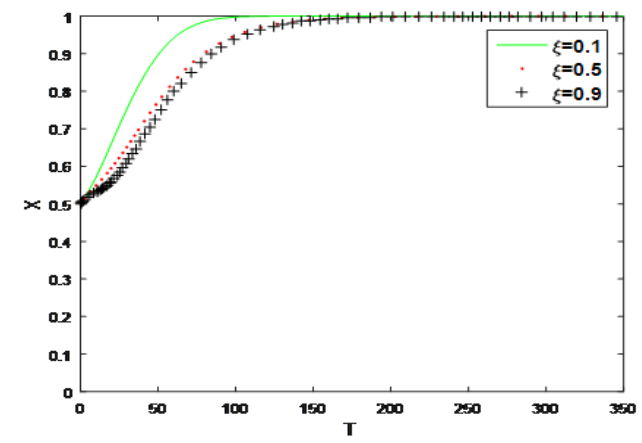

Figure 9 Evolution trend of the behavior of e-commerce retailers under different subsidy levels

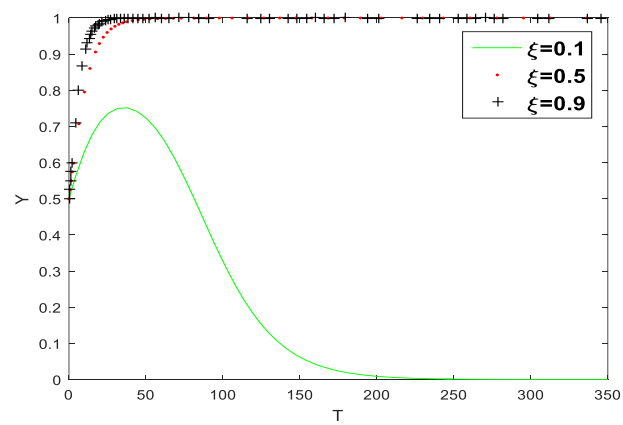

Figure 10 Evolution trend of the behavior of manufacturer under different subsidy levels 


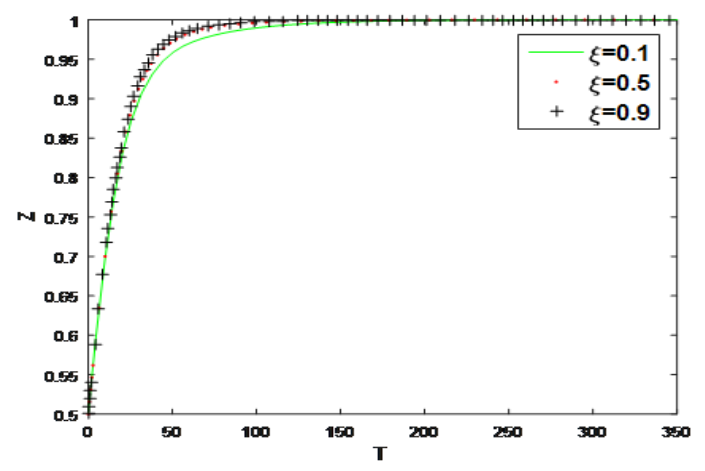

Figure11 Evolution trend of government regulation under different subsidy levels

E-Commerce retailers' strategies change over time as shown in Figure 9. To some extent, government subsidies to the manufacturer also have an impact on the behavior of e-commerce retailers. With the improvement of government subsidies for the manufacturer, the latter tend to produce organic food. The investment of organic technologies by the manufacturer improves food quality and brings more benefits to e-commerce retailers. The quality of organic food sold on e-commerce retailers has also been improved with the increasing responsibility of the manufacturer. At this time, in order to reduce costs, e-commerce retailers will relax their supervision over organic products sold on their platforms to a certain extent, so that the rate of their evolution towards responsibility will be relatively slow.

As shown in Figure 10, when the government's subsidies to the manufacturer are low, the manufacturer initially consider producing organic food, but soon move towards to the direction of non-production. This is mainly due to the initial stage of system evolution, in the face of the huge market space for organic food and government subsidies, some manufacturers with core competitiveness can still produce high-quality products, although this will take time as the technology of organic food production of Chinese manufacturers is not yet advanced and the production cost of organic food is relatively high. When the manufacturers find that it is difficult to bear the high costs and realize the high risk of non-conforming product, they will give up the production of organic food. When the government gives more subsidies, the cost of producing organic food will be reduced to some extent, and the initiative of production will be stimulated, thus promoting the manufacturers to evolve towards the choice of producing organic food.

Government regulation changes over time as shown in Figure 11. The speed of government's evolution towards active regulation gradually increases with the increase of its subsidies to the manufacturer. The government's subsidies to the manufacturer are expected to lead to the better responsibility of the manufacturer. Therefore, the government will strengthen the supervision of the manufacturer in order to improve the efficiency of government spending. As more and more manufacturers choose to produce organic food, the government should also supervise the production behaviors of manufacturers to a greater extent. As a result, the government evolves faster in a positive direction.

\subsection{The influence of the government's penalty for manufacturer on the evolution behavior}

\section{of the tripartite game}

$\omega$ takes the values of $0.1,0.5$ and 0.9 respectively, indicating that the government provides low-intensity, medium-intensity and high-intensity penalty for the manufacturer; and then the evolution trend of each subject of the game is as follows: 


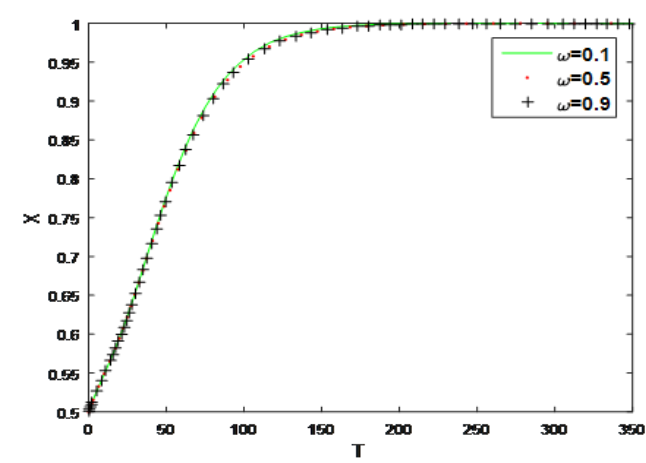

Figure 12 Evolution trend of the behavior of e-commerce retailers under different penalty levels

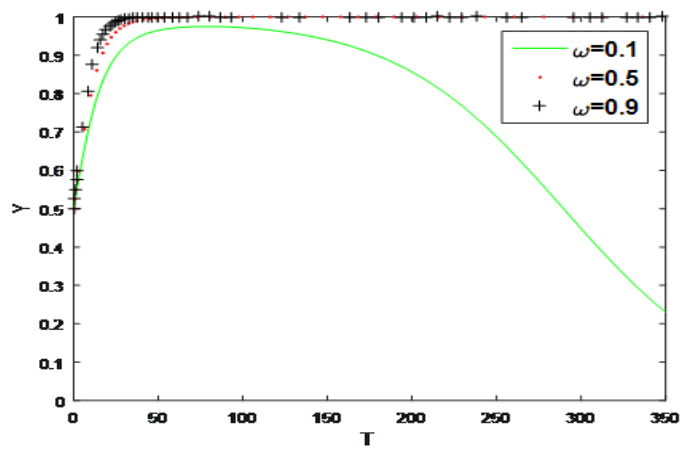

Figure 13 Evolution trend of the behavior of manufacturer under different penalty levels

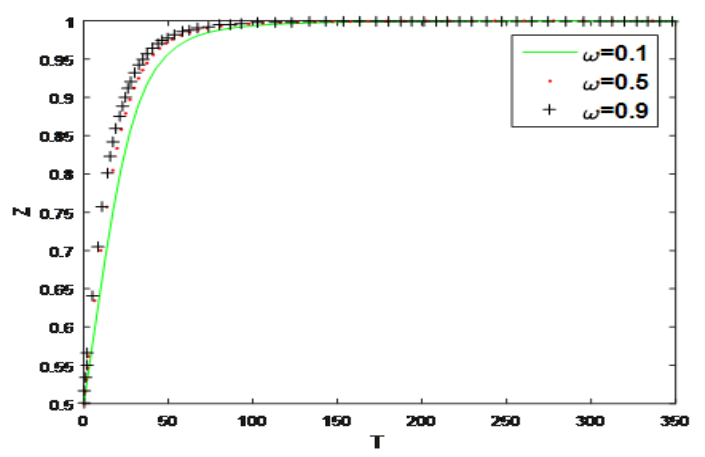

Figure 14 Evolution trend of government regulation behavior under different penalty levels

E-Commerce retailers' strategy changes over time as shown in Figure 12. As can be seen, when the government punishes the manufacturer that do not produce organic food and cause environmental pollution, e-commerce retailers will adopt the strategy of active supervision. Meanwhile, the change in the penalty intensity of the government has no obvious impact on the strategic choice of e-commerce retailers.

As shown in Figure 13, when the government penalty is low, the manufacturer first consider producing organic food, but as time passes the manufacturer will choose non-production strategies. This is because consumers in China still lack environmental protection awareness, and non-organic food still has a large market share. Although there may be a penalty for not producing organic food, the penalty is so small that manufacturers can still profit from producing non-organic food while abandoning the production of organic food with high technical and management requirements. Therefore, on the one hand, the government should increase the level of penalty for environmental pollution caused by non-production of organic food by manufacturers; on the other hand, it must also strengthen the education for consumers 
on environmental protection and encourage them to buy organic food that helps reduce environmental pollution, so as to promote the green transformation of the food industry.

The change of government's strategy over time is shown in Figure 14. It shows that as the penalty on the manufacturer is enhanced, the faster the government evolves towards active regulation. When the penalty intensity is too low, it is not enough to promote the production of the manufacturer. When the penalty intensity is increased, the environmental pollution caused by the production of non-organic food can be controlled. Therefore, with the enhancement of the government's penalty on manufacturers, the government will choose more active regulation strategies.

\subsection{The influence of the government's supervision intensity for manufacturer on the evolution}

\section{behavior of the tripartite game}

$\gamma$ takes the values of $0.1,0.5$ and 0.9 , respectively, indicating that the government provides low-intensity, medium-intensity and high-intensity supervision for the manufacturer, and then the evolution trend of each party of the game is as follows:

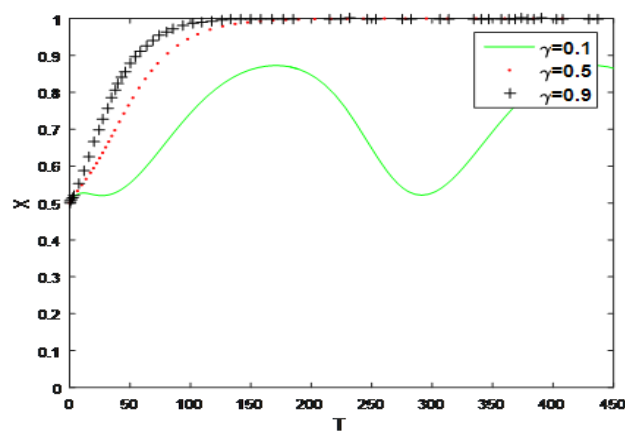

Figure 15 Evolution trend of the behavior of e-commerce retailers under different supervision levels

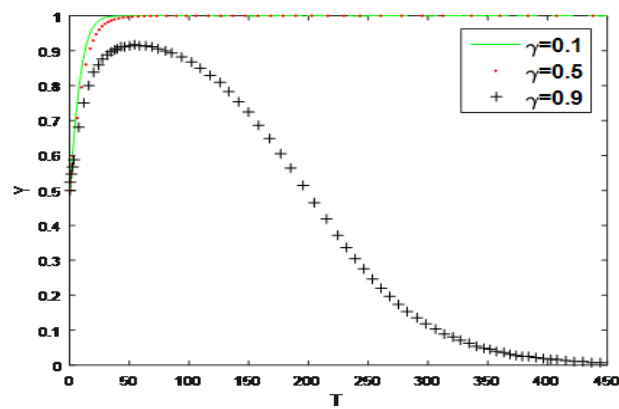

Figure 16 Evolution trend of the behavior of manufacturer under different supervision levels

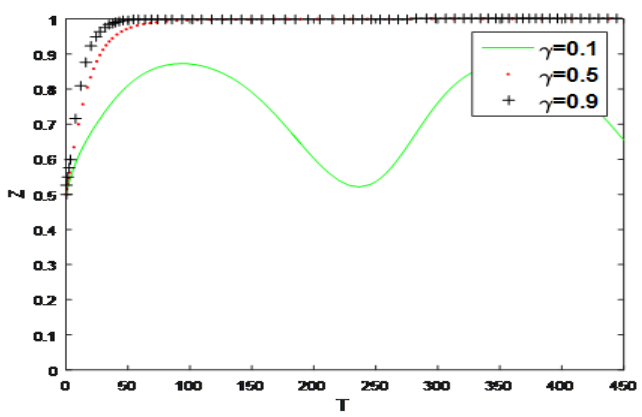

Figure 17 Evolution trend of government regulation behavior under different supervision levels

The strategy of e-commerce retailers changes over time as shown in Figure 15. When the 
government conducts low-intensity supervision over the manufacturer there is no evolutionary stability equilibrium point in the system. However, as the government's supervision intensifies, e-commerce retailers will evolve to actively fulfill their responsibilities.

As shown in Figure 16, the strategy of the manufacturer changes over time. When the government's supervision is low, the manufacturer will evolve to the strategy of producing organic food. When the government adopts high-intensity supervision, the probability of the manufacturer choosing to produce organic food increases at the beginning, but with the passage of time, the manufacturer will eventually evolve to the strategy of no production. This is because in China, the development of organic food industry in its infancy and the production technology is immature. There are still many key technologies need to be solved in the production process. Even if received government subsidies, manufacturers are unable to get breakthrough in the short term, which will produce substandard products. However, faced with its huge market prospects, manufacturers will choose to try to produce new products. When the government adopts high-intensity supervision, the products of the manufacturers are difficult to meet the quality standards stipulated by the government. Faced with the punishment brought by the high-intensity supervision of the government, the manufacturers will eventually give up trying technological innovation after weighing the expected benefits and costs, which is not conducive to the development of the organic food industry.

The change of government strategy over time is shown in Figure 17. It shows that when the government conducts low-intensity supervision over the manufacturer, the system has no evolutionary stability equilibrium point. The stronger the supervision of manufacturers, the faster the government will evolve towards active regulation.

\section{Conclusions and management insights}

\subsection{Discussion and conclusion}

With the improvement of people's living standards and the great concern of the society for sustainable development, it has become an inevitable requirement for the sustainable development of the food supply chain to prompt enterprises to fulfill their social responsibilities and provide safe and pollution-free organic food to the market. However, in developing countries such as China, on the one hand, the backward production technology of organic food greatly limits the production capacity of manufacturers, on the other hand, most enterprises have a weak sense of social responsibility. Therefore, relying solely on market mechanisms to guide enterprises to actively perform their duties has great uncertainty. As an important external force, the government can play an active role in promoting the organic food supply chain enterprises to fulfill their social responsibilities.

Existing studies lack consideration of fraudulent subsidies claiming behavior by manufacturers and generally ignore the dereliction of responsibility by e-commerce retailers which have developed rapidly in recent years. This paper establishes an evolutionary game model of government, organic food manufacturers and e-commerce retailers, and analyzes the influence of government regulation in terms of both subsidy and punishment on the evolutionary path and stability process of the behavior of manufacturers and e-commerce retailers. The conclusions are as follows:

(1) Government regulation can help to restrain the occurrence of corporate default in organic 
food supply chain and promote enterprises to fulfill their responsibilities. Zhang et al. (2016) also found that government regulation has a positive regulating effect on CSR fulfillment in supply chain. Our research considers the more of the scene, in particular, the government funding for e-commerce retailers and manufacturers, the punishment to e-commerce retailers for not performing their duties and manufacturers for not producing organic food, and the supervision to manufacturers for fraudulent subsidies claiming behavior will have an impact on the social responsibility of organic food supply chain enterprises.

(2) When the government's subsidies on technology and R \& D are too low, it is not enough to promote the production of organic food. When the penalty for nonorganic production behavior of manufacturers is low, it is not enough to restrict the manufacturers, and the greater the subsidy and penalty, the more conducive to the evolution of manufacturers to produce organic food. This is similar to the findings of Cui (2018), which from the perspective of penalty and subsidies, pointed out that the government should increase the penalty for nonorganic production and subsidies for organic food production.

(3) The government's moderate supervision of manufacturers can promote the production of organic food. For manufacturers, medium intensity supervision is helpful for them to fulfill their responsibilities actively. It is difficult for low-intensity supervision to avoid the fraudulent subsidies claiming behavior of manufacturers, but high-intensity supervision will inhibit the orderly development of organic food industry. As far as we know, the existing studies have not taken this into consideration.

(4) The government should provide appropriate support to e-commerce retailers, which will help them to fulfill their responsibilities actively. The excessive funding will make e-commerce retailers over rely on government subsidies. The greater the fine of the government for the behavior of the e-commerce retailers' breach of responsibility, the more conducive to the fulfillment of social responsibility of e-commerce retailers. Unlike the Shen (2017) study, which pointed out that the government should increase the fine of e-commerce retailers. Besides fine, this research also study the government subsidies, and find that appropriate subsidies to e-commerce retailers can also help them to actively fulfill their responsibilities and strengthen the supervision of organic food sold on their platforms.

\subsection{Theoretical Insights}

The theoretical significance of this study includes the following two aspects. Firstly, this paper expands the applicability of the game theory method in regulating the negligence behavior of organic food supply chain enterprises. Moreover, this analysis can also be applied to more general environments, in which agents have bounded rationality and dereliction of responsibility may occur. Secondly, our study found that government regulation of organic food supply chain enterprises, including manufacturerss and e-commerce retailers, can restrain their irresponsible behaviors. The findings are significant because the Chinese government has introduced several policies to promote the organic food industry as an important way to improve food safety, but they don't seem to be sufficient to urge enterprises to fulfill their responsibilities. Therefore, it is necessary to start from the perspective of the regulation of organic food supply chain in order to effectively govern the negligence behavior of enterprises.

\subsection{Management Implications}

The management inspiration of this study includes the following two aspects. First, government 
subsidies help curb the irresponsibility of organic food manufacturerss. The cost of producing organic food is much higher than that of ordinary food, so the government can encourage manufacturers to strengthen the research and development of organic food and the application of organic technology by means of subsidies, so as to reduce the cost of organic food manufacturerss and encourages them to actively produce organic food. Second, government needs to strengthen the supervision of non-organic food production, especially to punish the fraudulent subsidies claiming behavior. Only the combination of supervision and subsidies can effectively govern the behavior of organic food manufacturers. Third, in China and other countries where organic food is in the development stage, the government's supervision on organic food should not be too high, which will affect the enthusiasm of organic food manufacturers. However, the low level of supervision does not help to curb the irresponsible behavior of manufacturers. Therefore, the government should carefully choose the medium level of supervision. Fourth, the government can appropriately guide e-commerce retailers by means of financial support and fine, so as to strengthen the inspection of organic food sold, and promote the manufacturers to improve the level of social responsibility. Fifth, the government cannot give too much financial support to e-commerce retailers, which will lead to the dependence of e-commerce retailers on government funding. Therefore, the government should carefully adopt the policy of medium-level funding when formulating the policy of funding ecommerce retailers that sell organic food.

\subsection{Limitations}

This paper has the following limitations: First, due to the limitations of the evolutionary game model, the main body of the game does not include consumers. Consumers can be considered as a variable to be introduced into the dynamic evolutionary game model for analysis in the future. Second, due to the limitation of the conditions, the parameter assignment of the payoff matrix only reflects the general situation and lacks the support of the actual data. This is also a direction for further research.

\section{References}

Augustin-Jean, Louis, Jean P.P., 2018. Risk and Food Safety in China and Japan: Theoretical Perspectives and Empirical Insights. Routledge.

Chen, Y.H., Wen, X.W., Wang, B., Nie, P.Y., 2017. Agricultural pollution and regulation: how to subsidize agriculture?. Journal of Cleaner Production, 164(oct.15),258-264.

Cui, H., Wang, R., Wang, H., 2020. An evolutionary analysis of green finance sustainability based on multi-agent game. Journal of Cleaner Production, 269, 121799.

Dewey-Mattia, D., Manikonda, K., Hall, A.J., Wise, M.E., Crowe, S. J., 2018. Surveillance for Foodborne Disease Outbreaks — United States, 2009-2015. Surveillance Summaries. 67(2), 1-11.

Fan, B., Li, C.X., 2011. Evolutionary game analysis on hidden irregularity of processing enterprises in dairy supply chain. International Conference on Management Science and Engineering - Annual Conference Proceedings. 477-482.

FSAI Survey Finds Horse DNA in Some Beef Burger Products. 15 January 2013. Food Safety Authority of Ireland. https://www.fsai.ie/details.aspx?id=11878

Liu, Y., Liu, F., Zhang, J., Gao, J., 2015. Insights into the nature of food safety issues in 
beijing through content analysis of an internet database of food safety incidents in china. Food Control. 51, 206-211.

Mao,X.q.,2019. Green food, new era, start again -- a summary of China's green food industry development. Rural Work Newsletter.747(7),40-45.( In Chinese)

Mittal, V.K., Sangwan, K.S., 2014. Prioritizing Barriers to Green Manufacturing: Environmental, Social and Economic Perspectives. Procedia CIRP. 17, 559-564.

Naik, G., Suresh, D. N., 2018. Challenges of creating sustainable agri-retail supply chains. IIMB Management Review, 270-282.

Nie, W., Li, T., Zhu, L.,2020. Market demand and government regulation for quality grading system of agricultural products in china. Journal of Retailing and Consumer Services, 56.

Nie, Z., Heerink, N., Tu, Q., \& Jin, S., 2018. Does certified food production reduce agrochemical use in China? China Agricultural Economic Review, 10(3), 386405.

Ni, X.Z., 2012. Research on the effective supply of green agricultural products in China. Issues in Agricultural Economy. 4,18-21.(In Chinese)

Papadopoulos, S., Zafeiriou, E., Koutroumanidis, T., 2018. Organics or not? prospects for uptaking organic farming. New Medit, XVII(1), 13-22.

Patel, J., Modi, A., Paul, J., 2017. Pro-environmental behavior and socio-demographic factors in an emerging market. Asian Journal of Business Ethics. 6, 189-214.

Paul, J., Modi, A.G., Patel, J.D., 2016. Predicting green product consumption using theory of planned behavior and reasoned action. Journal of Retailing and Consumer Services. 29(29), 123-134.

Pouliot, S., Wang, H. H.,2018. Information, incentives, and government intervention for food safety. Annual Review of Resource Economics, 10(1), 83-103.

Rtomir, R., Karmen, P., Miroljub, K., Martina, B., Andrej, K., 2013. The dynamic simulation of organic farming development scenarios - a case study in slovenia. Computers and Electronics in Agriculture, 96, 163-172.

Styles, D., Schoenberger, H., \& Galvez-Martos, J.L., 2012. Environmental improvement of product supply chains: A review of European retailers' performance. Resources, Conservation and Recycling, 65: 57-78.

Song, C., Zhuang, J., 2016. Regulating food risk management-a governmentmanufacturer game facing endogenous consumer demand. International Transactions in Operational Research, 25(6),1855-1878.

Sun, H., Wan, Y., Zhang, L., Zhou, Z., 2019. Evolutionary game of the green investment in a two-echelon supply chain under a government subsidy mechanism. Journal of Cleaner Production, 235(OCT.20), 1315-1326

Tang, A.K.Y., Kee-hung, L., \& Cheng T.C.E., 2016. A multi-research-method approach to studying environmental sustainability in retail operations. International Journal of Production Economics, 171: 394-404.

Wang J.N., Zhang Y.H. et al., 2019. Study on the dynamic evolution of food enterprise safety risk driven by economic interests. Chinese Journal of Management Science, 27(12), 113-126.(In Chinese)

Wu, X., Lu, Y., Xu, H., Lv, M., Hu, D., He, Z., Liu, L., Wang, Z., Feng, Y., 2018. 
Challenges to improve the safety of dairy products in China. Trends in Food Science \& Technology. 76, 6-14.

Yan, H. N., Jing, Y. U., 2018. An Investigation of the Dilemma of the Mobilized Governance of the Food Security of Online Meal Ordering: A New-Institutional Analytical Framework. Journal of Beijing Administration Institute. 20(3),8190.(In Chinese)

Yinghua, S., Ningzhou, S. , Dan, L., Lima, S. , \& Á Rocha., 2018. Evolutionary game and intelligent simulation of food safety information disclosure oriented to traceability system. Journal of Intelligent \& Fuzzy Systems, 35(3), 2657-2665.

You, H., Zhang, X., 2016. Ecoefficiency of Intensive Agricultural Production and Its Influencing Factors in China: An application of DEA-Tobit Analysis. Discrete Dynamics in Nature and Society. 2016(5), 1-14.

ZHANG, H., LIU, Y.,2018. An Evolutionary Game Model of Online-food Safety Regulation. 2018 8th International Conference on Logistics, Informatics and Service Sciences (LISS). 1-5.

Zhang, H. , \& Tang, L., 2019. A nash equilibrium game model for seafood safety regulation. Journal of Coastal Research, 94, 818-822.

Zhang, J., Yu, Y., 2007. Technology Diffusion, Government Policy and Agricultural Sustainable Development. International Conference on Management Science and Engineering. 2214-2219.

Zhang, L., Long, R., Huang, Z., Li, W., Wei, J., 2020. Evolutionary game analysis on the implementation of subsidy policy for sustainable transportation development. Journal of Cleaner Production, 267, 122159.

Zhang X.H., March 14, 2017. Food fraud is prominent: falsely labeled as green and organic, mixed drinks become fresh squeezed. Xinhuanet. http://finance.sina.com.cn/consume/puguangtai/2017-03-14/docifychhus1153805.shtml

Zhao, L., Wang, C., Gu, H., Yue, C.,2017. Market incentive, government regulation and the behavior of pesticide application of vegetable farmers in china. Food Control, 85,308-317.

Zheng, S., Xiao, M., MIAO, Z., 2017. Nitrogen Losses in Paddy Field Drainage Modified by Different Water Level Regulations. Polish Journal of Environmental Studies. 26(3), 1393-1401. 